\title{
1 Marine dual fuel engine modelling and parametric investigation of engine settings effect 2 on performance-emissions trade-offs
}

3 Sokratis Stoumpos ${ }^{\mathrm{a}, 1}$, Gerasimos Theotokatos ${ }^{\mathrm{a}, 1}$, Evangelos Boulougouris ${ }^{\mathrm{a}}$, Dracos Vassalos ${ }^{\mathrm{a}}$, Iraklis 4 Lazakis $^{\mathrm{b}}$, and George Livanos ${ }^{\mathrm{c}}$

5 a Maritime Safety Research Centre, Department of Naval Architecture, Ocean and Marine 6 Engineering, University of Strathclyde, 100 Montrose Street, Glasgow, G4 0LZ, Scotland, UK

$7{ }^{\mathrm{b}}$ Department of Naval Architecture, Ocean and Marine Engineering, University of Strathclyde, 100

8 Montrose Street, Glasgow, G4 0LZ, Scotland, UK

$9{ }^{\mathrm{c}}$ Department of Naval Architecture, Technological Educational Institute of Athens, Egaleo, Greece

$10{ }^{1}$ These authors contributed equally to this work.

\section{ABSTRACT}

12 The continuous stringent requirements of the environmental regulations along with the LNG fuel 13 penetration and the development of port and bunkering facilities, render the use of the dual fuel engines an attractive alternative of the traditional ship propulsion plants based on Diesel engines running with HFO for reducing both the plant operating cost and environmental footprint. The present study deals with the computational investigation of a large marine dual fuel (DF) engine of the fourstroke type for comparing its performance and emissions, in both diesel and gas mode operation by using the commercial software GT-ISE. The engine diesel model was initially set up and calibrated to adequately represent the engine operation. Subsequently, the engine dual fuel model was further developed by considering the injection of two different fuels; methane in the cylinder inlet ports and pilot diesel fuel into the engine cylinders. The derived results were analysed for revealing the differences of the engine performance and emissions at each operating mode. In addition, the turbocharger matching was investigated and discussed to enlighten the turbocharging system challenges due to the completely different air-fuel ratio requirements in diesel and gas modes, respectively. Finally, parametric simulations were performed for gas mode operation at different loads by varying pilot fuel injection timing, inlet valve closing and inlet manifold boost pressure, aiming to identify the engine settings that simultaneously reduce $\mathrm{CO}_{2}$ and $\mathrm{NOx}$ emissions considering the air-fuel ratio operation window limitations. The parametric study results are discussed to infer the engine optimal settings. 
30 Keywords: marine dual fuel four-stroke engines; low pressure gas injection, GT-ISE (GT-POWER) 31 simulation; turbocharging system requirements; performance-emissions comparison; parametric 32 investigation; engine optimal settings. 


\section{INTRODUCTION}

Marine diesel engines gaseous emissions including $\mathrm{CO}_{2}, \mathrm{NOx}, \mathrm{SOx}, \mathrm{HC}, \mathrm{CO}$ and $\mathrm{PM}$, have been steadily increasing throughout the last years. As it is reported in Bows-Larkin et al. (2014), shipping accounts for $2-3 \%$ of global gaseous emissions. For controlling gaseous emissions and air pollution as well as reducing the environmental impact of the maritime industry, various international and national regulatory bodies such as IMO, EMSA and EPA have adopted a series of regulations for limiting the non-greenhouse gaseous emissions including NOx and SOx, as well as the greenhouse gaseous emissions; mainly $\mathrm{CO}_{2}$ as illustrated in IMO (2014), EMSA (2015) and EPA (2015).

Through these amendments of the international regulatory framework, the Energy Efficiency Design Index (EEDI) and the Energy Efficiency Operational Indicator (EEOI) were introduced. Based on the aforementioned, the Ship Energy Efficiency Management Plan (SEEMP) was established. The EEDI was made mandatory for newly built ships on 2013 whilst SEEMP for new and existing vessels on 2011 with the adoption of amendments to MARPOL Annex VI. The expected benefits from the implementation of the above include not only the reduction of the environmental impact of gaseous emissions, but also the reduction of the fuel consumption throughout the ship lifetime leading to minimised operating costs that affect the competitiveness of the shipping companies as it is discussed in Theotokatos \& Tzelepis (2015). Furthermore, the price of LNG is also attractive; about $60 \%$ of the HFO price (Livanos et al., 2014), although the market is volatile and the fuels prices are affected by various parameters including geopolitical factors.

Responding to the imposed regulatory framework, the engine manufacturers e.g. MAN Diesel \& Turbo (2012) and Wärtsilä (2015), as well as Classification societies e.g. ABS (2013) performed studies focusing on the gaseous emissions reduction (Jean-Michael, 2012), (Hendrik et al., 2016), (Bouman et al., 2017). In addition, the engine manufacturers have undergone efforts to improve the combustion characteristics, in order to improve the engines efficiency and consequently to reduce the associated fuel consumption, as well as to limit the engines gaseous emissions. Marine engine manufacturers have also developed dual fuel (DF) versions both for the large two-stoke slow speed engines and the small to medium size, four-stroke engines. These engines have the ability to operate 
60

on the gas and diesel modes; in the former by using natural gas and pilot diesel fuel, in the latter by burning diesel fuel (HFO or MGO).

As it is discussed in Livanos et al. (2014) and Abdelrahman et al. (2016), natural gas (NG) is the greenest fossil fuel that forms a well proven and feasible solution for ships propulsion. Whilst the conventional diesel fuels will remain the main preference for the majority of the existing vessels in the near future, the commercial opportunities of the natural gas are attractive for new-built vessels. The sulphur content of natural gas is almost zero (about $0.004 \%$ by mass), which is well below the 0.1\% limit required for ECAs from 2015, and therefore the SOx emissions of the engines operating in gas mode are very limited (SOx emissions can be reduced up to $90-95 \%$ compared with the diesel mode operation at HFO). In addition, the DF four-stroke engines with low pressure admission can achieve up to $85 \%$ NOx emissions reduction as they operate in the lean burn combustion concept, the $\mathrm{CO}_{2}$ emissions can decrease up to $20-25 \%$ due to the natural gas lower carbon to hydrogen ratio, whereas the particulate matter (PM) emissions are almost eliminated and there is no visible smoke during engine operation at gas mode.

There are two types of four-stroke engines differing in the gas injection; (a) the DF engines which operate at low gas pressure (5-7 bar) where the gas is injected at port and mixes with air during the intake phase (Wärtsilä, 2015) and (b) the gas-diesel (GD) engines which operate at high gas pressure (around 350 bar) where the gas is directly injected into the cylinder during the combustion phase. Both categories can achieve typical brake mean effective pressure (BMEP) of around 25 bar. Typical example of the first type is the Wärtsilä 50DF category whereas Wärtsilä 32 GD and 46 GD are classified under the second type (Jarf \& Sutkowski, 2009). Likewise, there are two types of twostroke DF engines classified by the gas injection and combustion processes concept; the first operates at high gas fuel pressure (around 300-350 bar) in which the gas fuel is injected during the combustion phase and is burnt according to the diffusive combustion concept as described in MAN Diesel \& Turbo (2015), whereas the second operates in low gas fuel pressure (around 7 bar) in which the gas fuel is injected into the engine cylinder during the compression phase and burnt based on the premixed combustion concept as explained in Nylund et al. (2013). 
Previous research efforts on dual fuel engines along with a review of the operation principles and practices are reported in Karim (2015). The research efforts reported in Krishnan et al. (2002), Cordiner et al. (2005), Kavtaradze et al. (2005), Srinivasan et al. (2006), Vasilev (2007), Ozcan et al. (2008), Papagianakis et al. (2010), Pirker et al. (2010), Jarvi (2010), Andre (2013), Xu et al. (2014), Abagnale et al. (2014), Yousefi et al. (2015), Bo et al. (2015), Li (2016), Qiang et al. (2015), Zhongshu et al. (2015), Banck et al. (2016), Cameretti et al. (2016), Moriyoshi et al. (2016), Shinsuke et al. (2016), Wang et al. (2016), Georgescu et al. (2016) mainly dealt with the investigation of the dual fuel engines emission characteristics, the development of methods for increasing the DF engines efficiency, the optimisation of the pilot fuel injection and gas substitution rate, the extension of the operating range of gas mode and avoiding knocking. Simulation tools of various complexities (0D to 3D) (Singh et al., 2004), (Merker et al., 2006), (Coble et al., 2013), (Ritzke et al., 2016), (Theotokatos et al., 2016), (Mavrelos et. al., 2018) have been used for investigating the DF engine steady state performance and transient response (Xu et al., 2014), (Shuonan et. al., 2014). For analysing marine engines and ship propulsion systems, various model types have been also used as described in Benvenuto et al. (2013), Theotokatos \& Tzelepis (2015), Baldi et al. (2015), Cichowicz et al. (2015) and Mizythras et al. (2018). However, very few studies have been published focusing on marine DF engines investigations. The control during fuel mode transition of a marine DF engine has been reported in Wang et al. (2015). Nylund (2007), Boeckhoff et al. (2010), Portin (2010), Mohr \& Baufeld (2013), Mohand et al. (2013), Menghan et al. (2015), Weifeng et al. (2015) and Sixel et al. (2016) focused on experimental studies of marine DF engines reported providing details of the engine settings and operation, whereas a computational study of DF engine investigating the alternatives of turbocharging system, compression ratio and variable valve timing is reported in Christen \& Brand (2013), where the DF engine combustion was modelled by considering the gas fuel only assuming limited contribution of the pilot fuel. Sixel et al. (2016) combined GT-Power with a developed combustion model and experiments to investigate a marine DF engine operating with either natural gas or menhanol.

In this respect, the main objective of the present study is to develop a model for a large marine dual-fuel engine of the four-stroke type, considering the engine processes and systems. Based on this, 
115 the investigation of the engine steady state performance and exhaust emissions is carried out at the 116 engine discrete operating modes (diesel/gas). By analysing the derived results, the processes that 117 affect the engine efficiency and gaseous emissions are revealed enabling the elaboration on possible 118 ways to increase the engine efficiency and reduce emissions. In addition, the turbocharger matching 119 along with the waste gate settings are discussed as different requirements are imposed in each 120 operating mode. Finally, the optimisation of the engine settings at the gas mode is investigated based 121 on a parametric study results and taking into account the $\mathrm{CO}_{2}$ and $\mathrm{NOx}$ emissions reduction along 122 with the engine operational limitations.

\section{ENGINE MODELLING}

\subsection{Investigated engine}

125 The Wärtsilä engine 9L50DF was used for the present study, which is a four-stroke, non126 reversible, turbocharged and intercooled DF engine. The engine consists of nine cylinders placed in127 line. This type of engine is widely used due to its high power output along with its fuel flexibility, low 128 emission rates, high efficiency and reliability. The engine details are reported in the manufacturer 129 project guide (Wärtsilä, 2015). The main engine characteristics are illustrated in Table 1. The engine 130 layout and components are presented in Figure 1. As it is shown, a waste gate is used to by-pass a part 131 of the exhaust gas from the turbocharger turbine in order to control the engine cylinders air-fuel ratio 132 at the gas operating mode. Each engine cylinder includes a main fuel and a pilot fuel injector. Gas is 133 injected by using solenoid valves at each cylinder inlet port (upstream the intake valves) during the engine induction process.

135 The engine operation at constant speed of $514 \mathrm{r} / \mathrm{min}$ was investigated in the present study. Engine 136 operation under these conditions can be found in electric propulsion systems, where engine-electric 137 generator sets are used for producing the ship required electric energy. 
Table 1 Engine main characteristics

\begin{tabular}{|l|l|l|}
\hline MCR power & $\mathrm{kW}$ & 8775 \\
\hline MCR speed & $\mathrm{r} / \mathrm{min}$ & 514 \\
\hline BMEP at MCR & $\mathrm{bar}$ & 20 \\
\hline BSFC at MCR (Diesel mode) & $\mathrm{g} / \mathrm{kWh}$ & 190 \\
\hline BSEC at MCR (gas mode) & $\mathrm{kJ} / \mathrm{kWh}$ & 7300 \\
\hline Bore & $\mathrm{mm}$ & 500 \\
\hline Stroke & $\mathrm{mm}$ & 580 \\
\hline No. of cylinders & - & 9 \\
\hline Turbocharger units & - & 1 \\
\hline
\end{tabular}

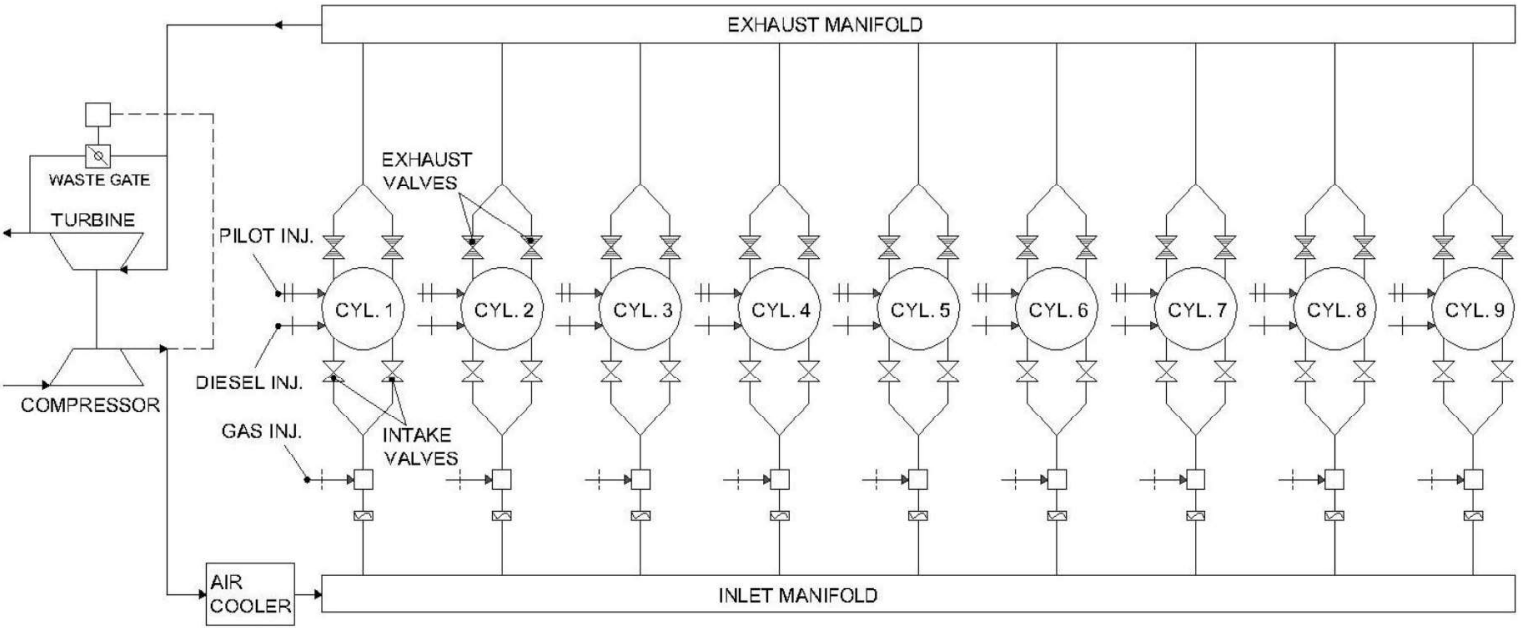

Figure 1 Engine layout

\subsection{Model set-up and calibration}

The software used in the present work is GT-ISE /GT-Power (Gamma Technologies, 2016), which is a widely used 1-D simulation program for engine modelling and analysis. GT-ISE is capable of, through a sophisticated set of solvers and algorithms, representing the physical processes within a working engine, to simulate the steady and transient states operation of various engine types. The main principle of the software is based on the ability of the user to build an accurate engine model in the software GUI, based on a broad range of items available in the software library. The software employs 1D gas dynamics to represent the flow in pipes, whereas 0D approach was used for the simulation of engine cylinders. Thus, it is able to predict the operating parameters of the engine and its components including pressures, mass flow rates and temperatures. The GT-ISE software is widely considered as one of the leading tools for these type of engine simulations due to its computational capabilities, results accuracy and fast execution time. In addition, the offered customisability and the 
153 coverage of a wide range of applications were considered advantageous characteristics for selecting 154 the GT-ISE software in the present study.

155 The data required for the modelling stage as input was acquired from the product guide and the 156 manufacturer engine 3D model presented in Wärtsilä (2015). Initially, the model for one-cylinder 157 block was developed and validated for the diesel mode operation and subsequently, the model was 158 extended to cover the dual fuel operation by adding an additional injector for the natural gas 159 connected to the cylinder inlet port. Then the complete engine model including the turbocharger, 160 waste gate and air cooler was developed as shown in Figure 2.

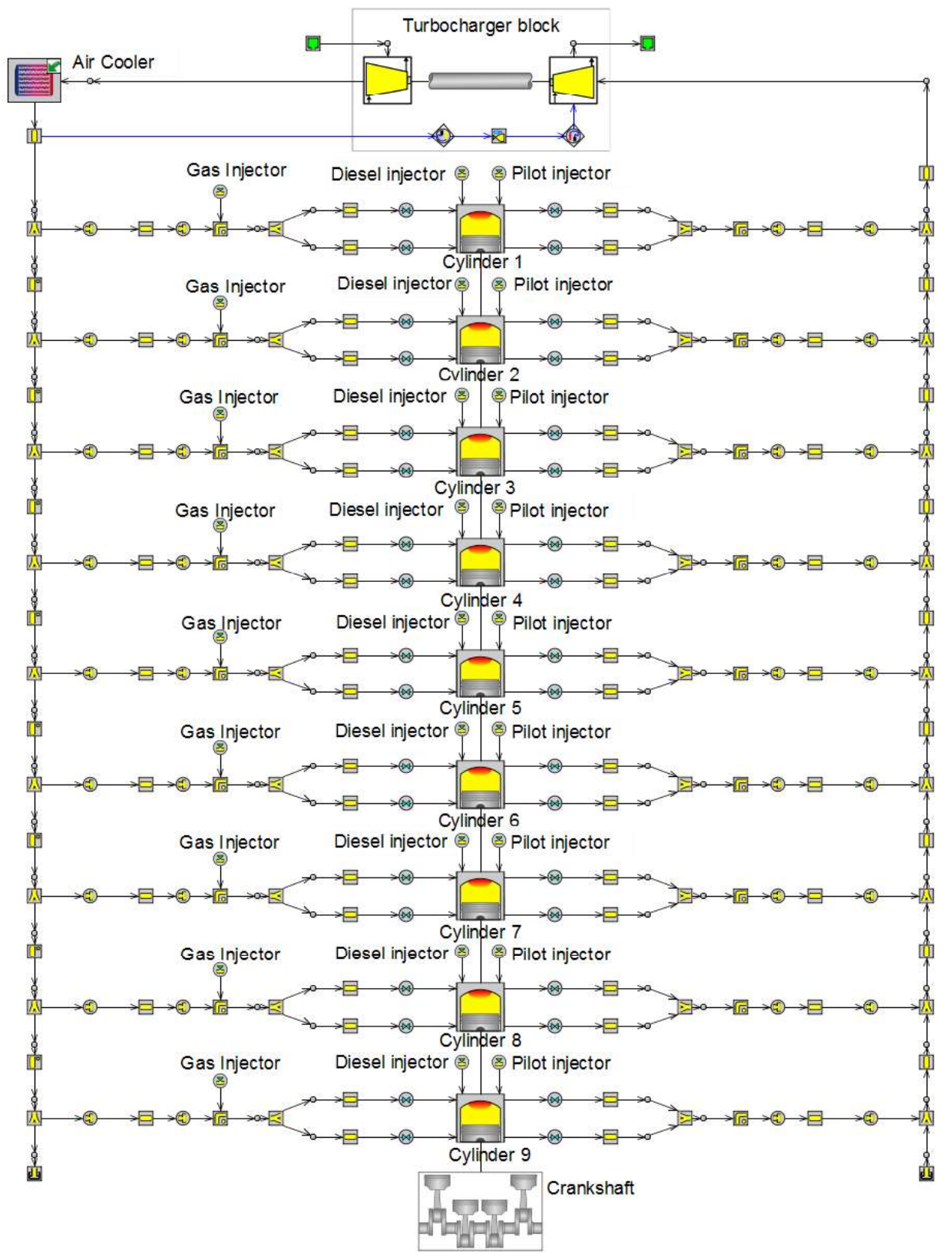

Figure 2 Engine model in the GT-ISE environment 
163 The steps required to set up the engine model are as follows. Initially, the component blocks are 164 selected, which sufficiently represent the engine layout and the appropriate interconnections are 165 established. Then, the input data of all blocks are set. Preliminary calibration of the model constants is 166 performed for a reference point and simulation runs are carried out. Finally, the fine tuning of the 167 model constants is accomplished, so that the required accuracy is obtained.

168 The input data needed to set up the model includes the engine geometric data, the intake and 169 exhaust valves profiles, the compressor and turbine performance maps, the waste gate geometric and 170 control details, the constants of engine sub-models (combustion, heat transfer and friction), the engine 171 operating point (load/speed) and the ambient conditions. Initial conditions are required for the 172 temperature, pressure and composition of the working medium contained in the engine cylinders, 173 pipes and receivers.

174 The Woschni heat transfer model initially presented in Woschni (1967) and extensively employed 175 in various studies as described in Merker et al. (2006) was used to calculate the in-cylinder gas to wall 176 heat transfer coefficient. The heat release rate was simulated according to single Wiebe model 177 reported in Merker et al. (2006) for the engine diesel operating mode, whilst in the case of the gas 178 mode, the multi-Wiebe model was utilised by imposing three different Wiebe curves corresponding to 179 the premixed combustion of approximately half of the pilot fuel, the diffusive combustion of the 180 remaining pilot fuel and the rapid burning of the gaseous fuel as well as the tail combustion of the cylinder residuals respectively. In this respect, the cumulative fuel burning rate for the gas mode is calculated according to the following equation (Gamma Technologies, 2016):

$$
x_{b}(\theta)=\sum_{i=1}^{3}\left[\left(\frac{F F_{i}}{\sum_{i=1}^{3} F F_{i}}\right) x_{b, i}(\theta)\right]
$$

184 where FF denotes the fraction of fuel per Wiebe Curve; i denotes the Wiebe function; and $\theta$ denotes 185 the crank angle ( the $1^{\text {st }}$ cylinder TDC at the closed cycle corresponds to 0 degrees CA).

186 The injection delay was estimated for the diesel mode according to the Sitkey equation as described 187 in Merker et al. (2006), whereas the ignition delay for the gas mode was approximated by using the 188 equations and data reported in Christen \& Brand (2013) and Sixel et al. (2016). 
189 For the simulation of the diesel mode operation, marine gas oil (MGO) was used as the considered 190 fuel type along with the injection timing and injected fuel amount, which were provided as function of 191 the engine load. For the gas mode, the amount of injected gaseous fuel per cycle (NG) was calculated 192 by considering the known gas specific energy consumption and the fuel lower heating value. The gas 193 fuel is injected at each cylinder intake port (upstream the inlet valves). The gas injection takes place 194 during the respective cylinder induction process after the exhaust valve closing point, so that all the 195 injected gas is inducted into the engine cylinders. The gas injection duration for each injector was 196 considered to be a function of engine load taking values in the region from 38 to 68 degrees CA (from 197 low to high loads), The engine valves timing was set according to the Miller timing concept in which 198 the intake valves of each cylinder close before bottom dead centre (BDC). This reduces the required 199 compression work and the combustion temperature resulting in higher engine efficiency and lower 200 NOx emissions, however, high boost pressure and as a result, compressor pressure ratio values are 201 needed.

202 For calculating NOx emissions, the Zeldovich model was used, which was calibrated only for $203100 \%$ load operation at diesel and gas modes and subsequently was used to predict the NOx emissions 204 at the other investigated loads. A two-zone cylinder model was employed considering a zone 205 containing the combustion products and an unburned mixture zone. The temperature of the burned gas zone was used for estimating the NOx emissions. However, as the temperature spatial distribution was not calculated by the two-zone model, the NOx model is only capable of identifying trends and therefore, the derived results should be used with the necessary diligence.

Finally, the complete engine model with the air cooler, the turbocharger and waste gate was built for the diesel and gas modes. For the gas operating mode, the engine needs to operate within an air-fuel equivalence ratio in the range 2.0 to 2.3 for avoiding knocking and misfiring. This was achieved by controlling the waste gate valve to achieve a target value for boost pressure for each engine load. In GT-ISE, a PI controller was used to adjust the opening of the waste gate valve. 


\section{RESULTS AND DISCUSSION}

2215 The investigated marine DF engine steady state operation at both diesel and gas modes was 216 examined by performing simulation runs in a load range from $25 \%$ to $100 \%$ and constant engine 217 speed at $514 \mathrm{r} / \mathrm{min}$. A set of the derived results including the cylinder maximum (peak) pressure, the 218 indicated and brake mean effective pressures, the brake specific energy consumption, the brake

efficiency, the turbocharger shaft speed, the boost pressure, the exhaust gas temperature before and

after turbine along with their comparison to the respective available engine measured data from the 221 engine shop trials is presented in Figure 3.The predicted engine parameters including the air and 222 exhaust gas mass flow rates, the air-fuel equivalence ratio, the waste gate opening and the maximum 223 temperature of the burned zone as well as specific $\mathrm{NOx}$ and $\mathrm{CO}_{2}$ emissions are illustrated in Figure 4. 224 The normalised cylinder pressure diagrams for the $100 \%$ load is shown in Figure 5, whereas the 225 compressor operating points superimposed on the compressor map are presented in Figure 6. The 226 percentage errors between the measured and predicted parameters are reported in Table 2.

227 From the plots presented in Figure 3 and the data given in Table 2, it is derived that the obtained 228 accuracy was adequate (within the range of approximately $\pm 3 \%$ ). Therefore, it can be concluded that 229 the developed model can be used to sufficiently represent the engine steady state behaviour.

230 Table 2 Percentage error between the measured and the predicted values

\begin{tabular}{ccccc}
\hline \multicolumn{5}{c}{ Diesel mode } \\
\hline Load $(\% \mathrm{MCR})$ & $\mathrm{P}_{\mathrm{b}}$ & $\mathrm{p}_{\max }$ & $\mathrm{T} / \mathrm{C}$ speed & Eff \\
\hline 100 & 2.60 & 0.16 & 0.04 & -3.11 \\
85 & 2.36 & -0.60 & -0.02 & -2.90 \\
75 & 1.88 & 0.19 & -0.06 & -2.43 \\
50 & 1.14 & 0.42 & -0.79 & -1.64 \\
25 & 1.22 & 1.77 & 0.02 & -2.22 \\
\hline \multicolumn{5}{c}{ Gas mode } \\
\hline Load (\%MCR) & $\mathrm{P}_{\mathrm{b}}$ & $\mathrm{p}_{\max }$ & $\mathrm{T} / \mathrm{C}$ speed & Eff \\
\hline 100 & -0.42 & 0.37 & 0.75 & 2.49 \\
85 & -1.15 & 0.33 & -0.32 & 3.43 \\
75 & -0.41 & 0.51 & -0.90 & 2.32 \\
50 & 1.70 & 0.42 & -0.27 & -1.16 \\
25 & 1.34 & 0.60 & 1.14 & -0.90 \\
\hline
\end{tabular}


Table 3 Combustion model parameters for $100 \%$ load

\begin{tabular}{lcccc}
\hline \multicolumn{5}{c}{ Diesel mode } \\
\hline Fuel & $\mathrm{m}$ & $\Delta \theta$ & SOC & Fraction \\
\hline MGO & 1.25 & 56 & -3 & 1 \\
\hline Fuel & \multicolumn{6}{c}{ Gas mode } & & \\
\hline Premixed combustion & $\mathrm{m}$ & $\Delta \theta$ & SOC & Fraction \\
Main combustion & 3.5 & 15.3 & -16.7 & 0.02 \\
Tail combustion & 2 & 56.3 & -16.7 & 0.96 \\
\hline
\end{tabular}

Wiebe parameter "a" equals to 6.9 for all curves

The combustion models parameters values (as used in equations (1) and (2)) calibrated to simulate the diesel and gas modes at $100 \%$ load are summarised in Table 3. By considering the derived pressure diagrams (Figure 5), it can be inferred that the diesel mode combustion starts closer to the cylinder top dead centre (TDC), whereas in the case of the gas mode the pilot injection and combustion starts earlier to avoid knocking problems. The gas mode operation also results in a longer ignition delay due to the natural gas presence in the combustion chamber as it is also reported in Liu \& Karim (1997), Christen \& Brand (2013) and Sixel et al. (2016). The peak heat release rate of the dual-fuel combustion is slightly higher and the main combustion ends earlier than that at the diesel mode. However, lower maximum pressure level is observed in the case of the gas mode, which is attributed to the engine turbocharger operation at lower speed due to the waste gate valve opening. As the boost pressure is lower in the case of the gas mode, the cylinder pressure during the compression process is also lower; however due to the advanced start of combustion and the shorter combustion duration, the lower maximum pressure and the resultant lower friction, the engine brake power is retained at the same level as in the diesel mode.

Therefore, in terms of the engine power output and mean effective pressures behaviour, it can be observed that similar values were obtained in each operating mode; the indicated mean effective pressure of the diesel mode seems to be only slightly greater, however the brake mean effective pressures in both modes are exactly the same as the difference is compensated by the slightly higher friction mean effective pressure (due to the greater maximum pressure of the diesel mode).

In terms of the air-fuel equivalence ratio $(\lambda)$, it is observed from Figure 4 that in the gas mode the engine operates within a narrow $\lambda$ window with values between 2.0 and 2.3 ( 2.3 was observed at the 
255 low loads whilst 2.0 was obtained at medium and high loads). For the diesel mode, the obtained 256 values for $\lambda$ are slightly higher (in the range from 2.5 to 2.9 ), which means that more air passes 257 through the engine cylinders. For the gas operation, the waste gate opening affects (actually reduces) 258 the turbocharger speed, which in turn controls the boost pressure and as a result, the engine air flow 259 and $\lambda$. The obtained waste gate opening values were estimated in the range from $23 \%$ to $35 \%$ of the waste gate cross sectional area depending on the engine load.

As it can be seen in Figure 3 (turbocharger speed plot), figure 4 (mass flow rates plot) and figure 6 (compressor map), the turbocharger speed, pressure ratio and flow rate are considerably reduced in the gas mode when the engine operates at high loads. Smaller reductions can be observed at the lower loads $(25 \%$ and $50 \%)$. This denotes that the turbocharger matching needs special attention for a DF engine compared to the respective process for diesel or gas engines, as in the former case, the requirements for the two discrete modes need to be satisfied. Especially for the compressor selection, a number of parameters (usually contradictory) have to be considered including targeting operation in the high efficiency area and providing adequate margins to avoid the compressor surging and the turbocharger overspeed.

In terms of the engine efficiency at the two operating modes, it can be observed that the gas mode is more efficient at the high loads region obtaining values up to $47 \%$ at $100 \%$ load. When operating in the diesel mode, the engine obtains its highest efficiency at $75 \%$ load, whereas the engine efficiency only slightly varies in the load region from $70 \%$ to $100 \%$. For the gas mode, the efficiency decreases at a steeper gradient as the load decreases reaching its lowest value at $25 \%$ load; the engine obtains much higher efficiency at $25 \%$ load when operating at the diesel mode. This is attributed to the specific characteristics of diesel and gas operating modes as well as to the opening of the waste gate valve that results in lower turbocharger speed and pressure levels for the gas mode. Similar conclusions can be derived by analysing the brake specific energy consumption, which is the reciprocal of engine brake efficiency. The energy provided by the pilot diesel fuel accounts for $0.3 \%$ to $2.3 \%$ of the totally supplied fuel energy (the values increase with decreasing load).

Considering the calculated NOx and $\mathrm{CO}_{2}$ emissions shown in Figure 4, the following remarks can be noted. The specific NOx emissions are lower for the case of the gas mode operation; the NOx 
283 emissions for the diesel mode comply with Tier II limits, whereas the Tier III limit requirements are

284 satisfied for the gas mode. In addition, the lower specific NOx emissions value is obtained at $75 \%$ 285 load whilst higher values of the specific NOx emissions are obtained at lower and higher loads. In the 286 case of DF operation, NOx emissions slightly reduce at lower loads due to the premixed combustion 287 of natural gas at greater values of air-fuel ratio.

288 The NOx differences between the engine operating modes can be explained by considering the in289 cylinder burnt zone temperature plots (Figure 4) in conjunction with the cylinder pressure diagrams 290 (Figure 5) and maximum cylinder pressure (Figure 3). As it can be inferred from these figures, at the 291 diesel mode, the combustion occurs at greater pressure levels and the maximum temperature values of 292 the burnt zone are greater than the respective values obtained for the gas mode; therefore higher NOx 293 emissions are produced. On average, a reduction of $85 \%$ in NOx emissions is obtained when changing 294 the operating mode from diesel to gas.

295 The $\mathrm{CO}_{2}$ emissions of the gas mode are also reduced (by $25 \%$ in average) due to the lower carbon 296 to hydrogen ratio of the natural gas compared to the respective one of diesel fuel. Larger reduction is 297 obtained at the high loads region where the efficiency difference between the gas mode and diesel 298 mode is greater. In summary, it can be concluded that the engine environmental impact is much lower 299 when the engine operates at the gas mode. 

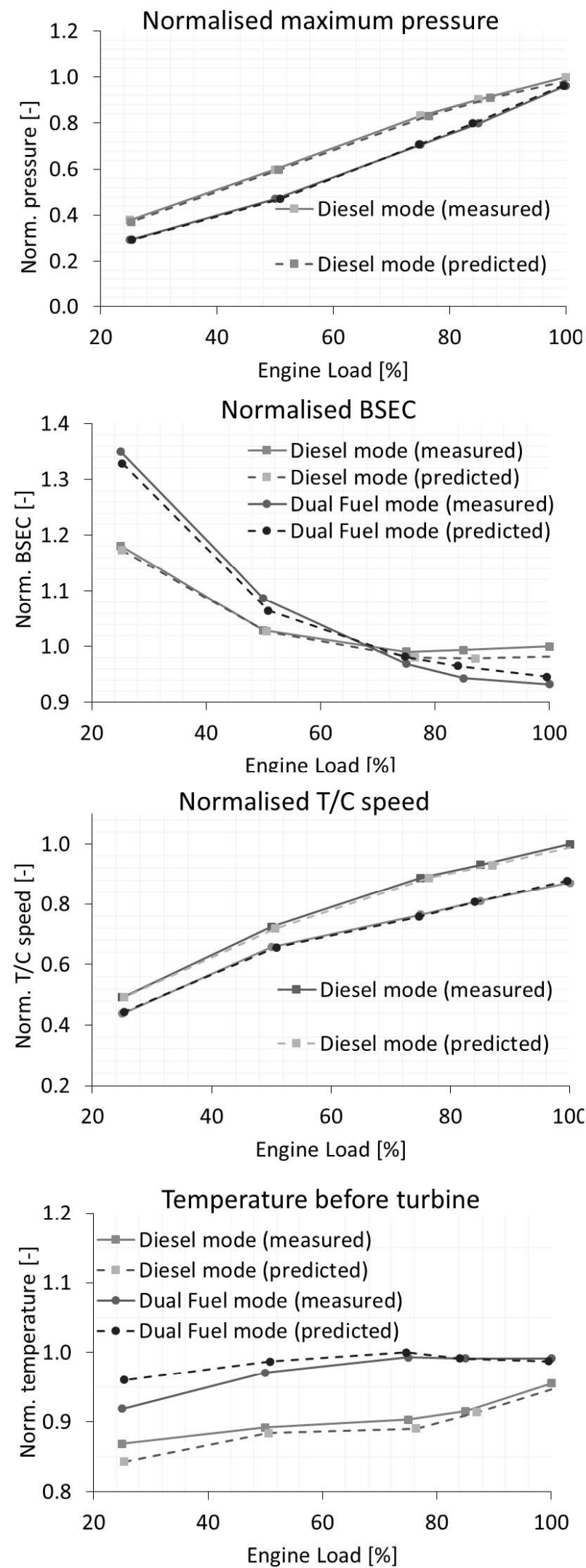
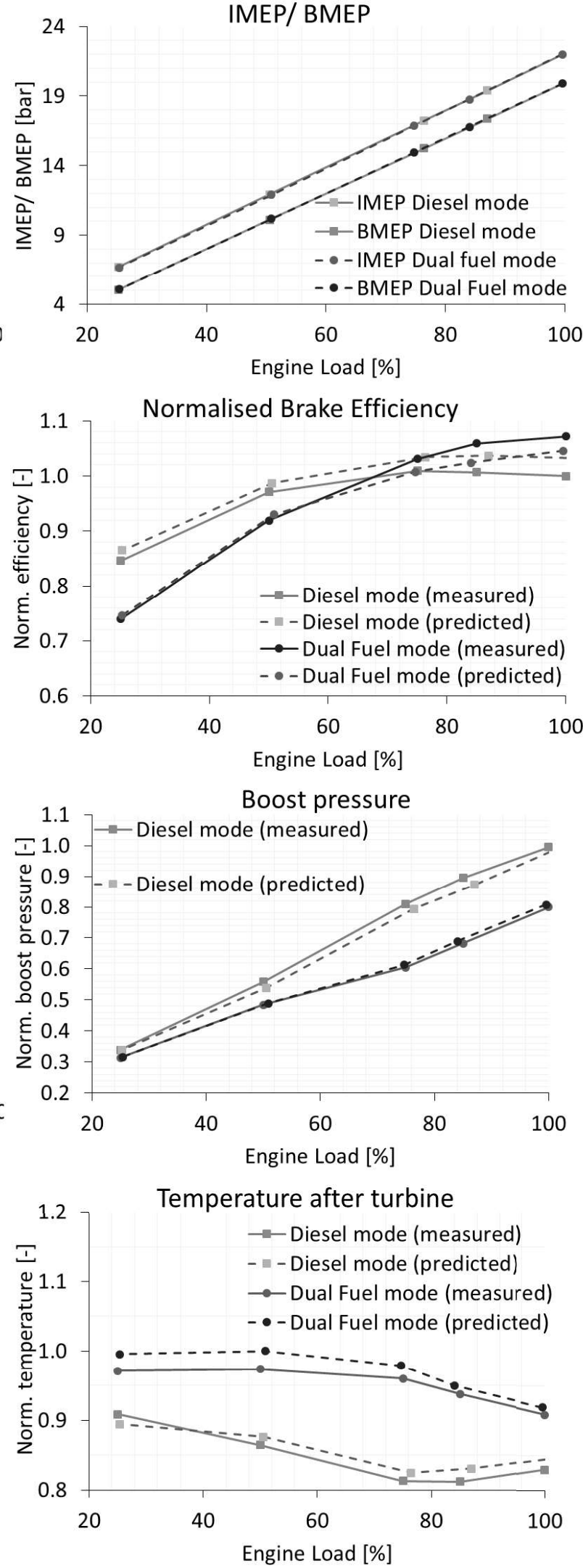

301 Figure 3 Simulation results and comparison with available experimental data. (The temperature plots were 302 normalised by using the values in K; the pressure plots were normalised by using the pressure absolute values). 

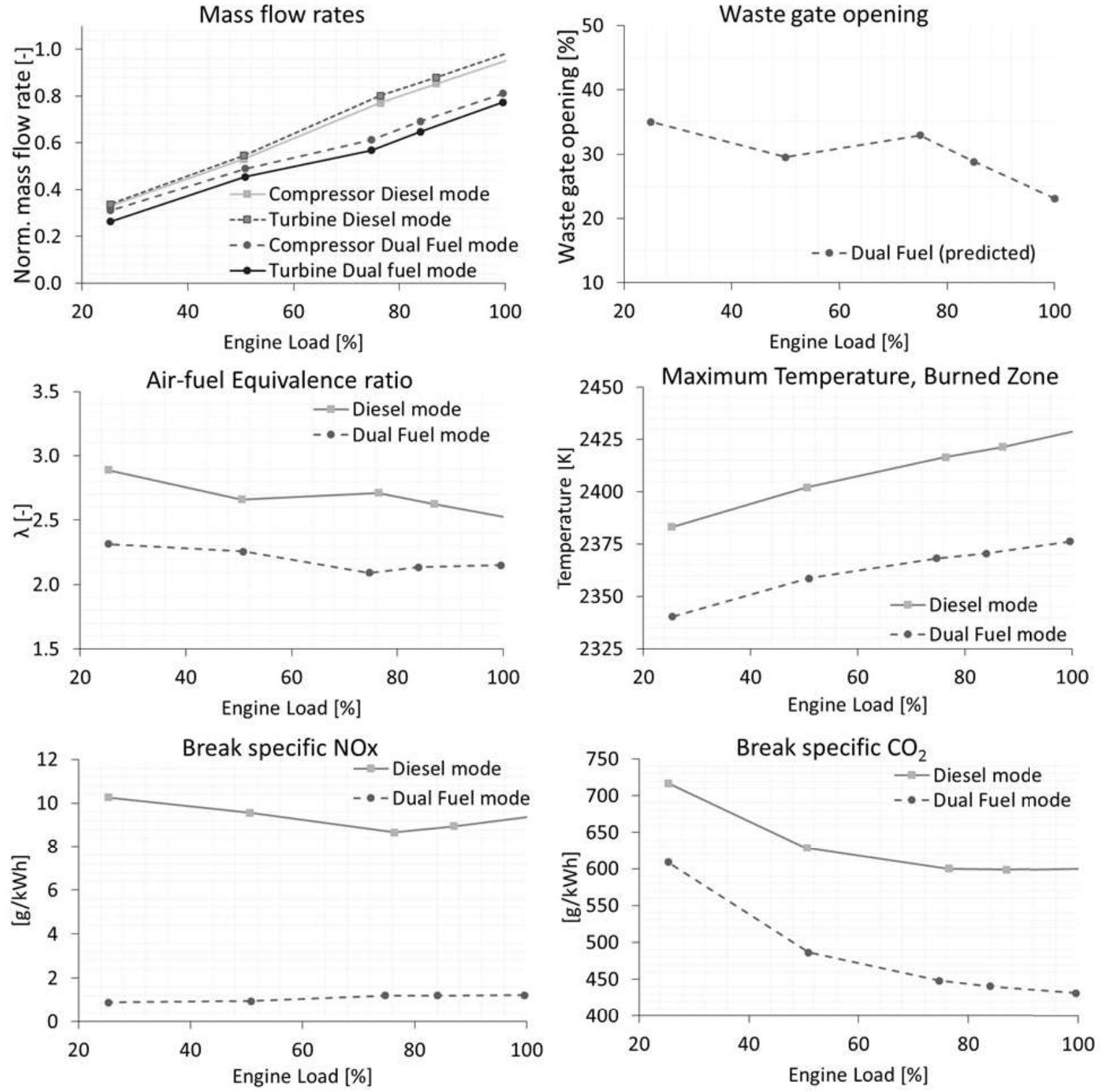

Figure 4 Predicted simulation results
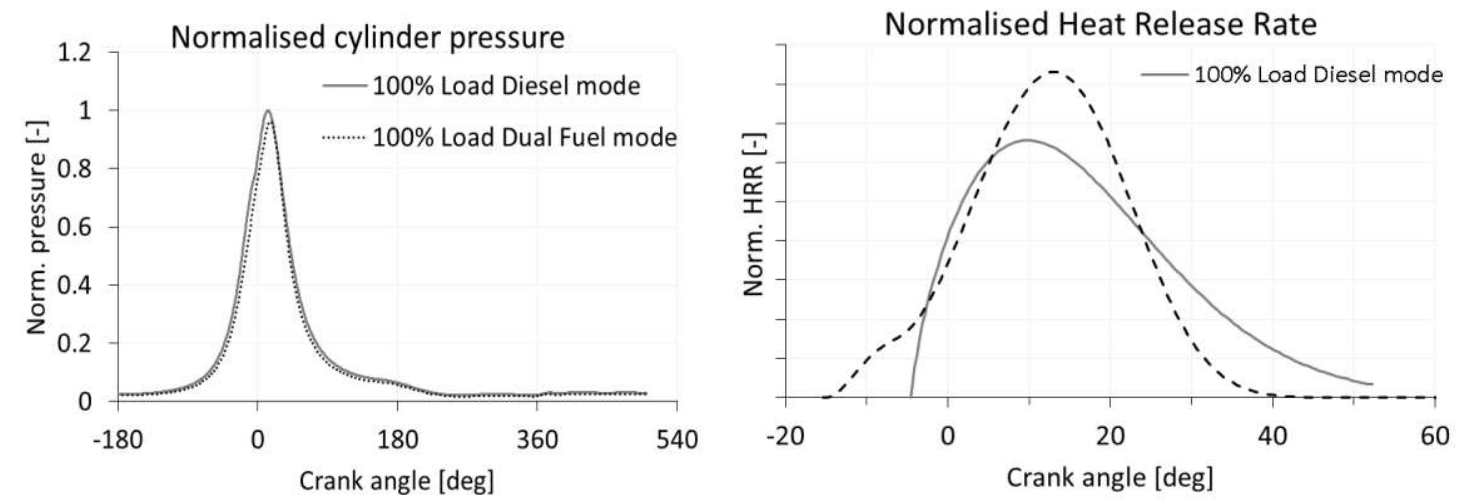

Figure 5 Pressure diagrams and heat release rates for diesel and dual fuel operation at $100 \%$ load 


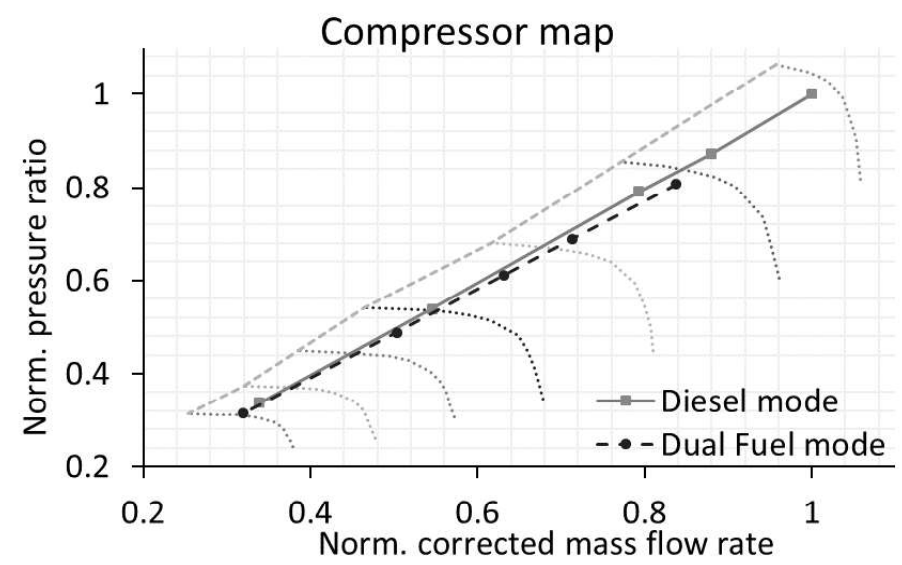

Figure 6 Compressor operating points superimposed on the compressor map for diesel and dual fuel operating modes

310 Having completed the engine model set up and the simulation of diesel and DF operating modes, a 311 parametric study was performed for optimising the DF engine settings aiming to a simultaneous 312 reduction of the $\mathrm{CO}_{2}$ and $\mathrm{NOx}$ emissions. It must be noted that the $\mathrm{CO}_{2}$ emissions are proportional to 313 the engine specific energy consumption and therefore, a decrease of $\mathrm{CO}_{2}$ emissions correspond to a 314 reduction of $\mathrm{BSEC}$ and an increase of the engine brake efficiency. The following parameters were 315 considered: pilot fuel injection timing ( -2 and +2 degrees CA from the reference value), inlet manifold 316 boost pressure $(-5 \%$ and $+5 \%$ from their reference value) and inlet valve closing $(-5$ and +5 degrees 317 CA from the reference value). The results derived for $75 \%$ load along with the reference points (taken 318 from the previously presented simulation results) are illustrated in Figure 7 . It can be inferred from 319 Figure 7 that the simultaneous reduction of $\mathrm{CO}_{2}$ and $\mathrm{NOx}$ can be obtained by operating the engine in 320 higher values of air-fuel equivalence ratio. However, the considered permissible lambda window 321 from 1.9 to 2.3 (to avoid knocking and misfiring, respectively) resulted in the exclusion of a number of the performed parametric runs points. The used start of injection (at the reference point) provides a compromise between the $\mathrm{CO}_{2}$ and the NOx emissions. Retarding the injection results in increased $\mathrm{CO}_{2}$ emissions and reduced NOx emissions and vice versa. Therefore, the reference value for the start of injection was only considered for the parametric runs for $50 \%$ and $100 \%$ loads presented below. As indicated in the bottom plots of Figure 7, the engine operation with increased air-fuel equivalence ratio values can be achieved either by increasing the boost pressure (by closing the waste gate valve that results in higher exhaust gas mass flow through the turbine and therefore, increasing the 
329 turbocharger speed or retarding the inlet valve closing that results in more air trapped in the engine 330 cylinder. A greater reduction potential for both $\mathrm{CO}_{2}$ and $\mathrm{NOx}$ emissions is obtained by increasing the 331 boost pressure as shown in the right-middle plot of Figure 7. The trade-off between the $\mathrm{CO}_{2}$ and the 332 NOx emissions as well as with the derived air-fuel equivalence ratio values are presented in Figure 8. 333 By excluding the points outside the considered lambda window as well as the points with $\mathrm{CO}_{2}$ and

NOx emissions higher than the respective reference values, a limited number of points can be identified for a potential engine optimisation. The optimised point can be then selected based on the preferred optimisation criteria. In Table 4, the optimised points are provided for the following cases: a) maximum simultaneous reduction of the $\mathrm{CO}_{2}$ and $\mathrm{NOx}$ emissions and b) maximum $\mathrm{CO}_{2}$ emissions reduction and NOx emissions equal or less than the respective reference point value. For the former, point No 2 is the optimised point with $5 \%$ greater boost pressure, $5^{\circ} \mathrm{CA}$ inlet valve closing retard and no change in the pilot injection start, which results in reductions by $0.9 \%$ and $6.5 \%$ in the $\mathrm{CO}_{2}$ and NOx emissions, respectively and an air-fuel equivalence ratio value equal to 2.21. Point No 3 having an additional pilot injection start advance of $2^{\circ} \mathrm{CA}$ (compared to point No 2) results in slightly greater air-fuel equivalence ratio (2.22) and reductions by $1.6 \%$ and $2.8 \%$ of the $\mathrm{CO}_{2}$ and $\mathrm{NOx}$ emissions, respectively. If lower lambda values are needed, point No 1 can be considered with increased boost pressure by $5 \%$ compared to the reference point, resulting in lambda equal to 2.09 and reductions by $0.6 \%$ and $3.8 \%$ in the $\mathrm{CO}_{2}$ and NOx emissions, respectively.

From the results presented in Figure 7 and Table 4 (the slopes of the respective curves), the relative significance of the three parameters used in the parametric runs can be identified. The inlet manifold boost pressure can be characterised as the main engine parameter for reducing both NOx and $\mathrm{CO}_{2}$ emissions, whilst, the inlet valve closing can be considered of lower significance. The pilot fuel injection timing is also a parameter that considerably affects the emissions as shown in Figure 7, however, it exhibits a contradictory influence on the $\mathrm{CO}_{2}$ and $\mathrm{NOx}$ emissions, as when the one increases, the other decreases and vice versa.

Furthermore, additional parametric runs were performed for $50 \%$ and $100 \%$ loads considering the reference point pilot start of injection and varying the boost pressure and the inlet valve closing. The derived $\mathrm{CO}_{2}-\mathrm{NOx}$ emissions trade-off and the air-fuel equivalence ratio values are presented in 
357 Figure 9. The permissible air-fuel equivalence ratio window for the case of $50 \%$ load was considered

358 to be wider than the one of the $100 \%$ load case (from 1.5 to 2.3 versus 2.0 to 2.4 , respectively) as 359 indicated in Wärtsilä (2015). The green marks represent points with the same settings as the points 1 360 and 2 at $75 \%$ load. As it can be inferred from the analysis of Figure 9 results, there is potential for 361 simultaneously reducing the $\mathrm{CO}_{2}$ and NOx emissions. A greater reduction can be obtained in the NOx 362 emissions ( 4.4 and $7.2 \%$ at $50 \%$ load 3.8 and $5.7 \%$ at $100 \%$ load), whereas the $\mathrm{CO}_{2}$ emissions 363 reduction is in the range of 0.7 to $0.8 \%$. However, the resulting lambda values are considerably high 364 (2.31 and 2.41) at 50\% load, whereas the respective values are 2.17 and 2.28 at $100 \%$ load. Therefore, 365 a boost pressure increase less than 5\% might be used for the other load points to avoid misfiring, thus 366 resulting in lower emissions reduction.

367 Another important parameter that needs to be considered in the engine optimisation study is the 368 unburnt hydrocarbon emissions and in specific, the methane slip for the DF engines. This was not 369 considered in this study as the 0D models cannot provide accurate results for the HC emissions, which 370 apart from the thermodynamic and thermochemistry parameters are greatly influenced by the 371 combustion chamber design. However, the parametric investigation study presented herein is quite 372 useful in the preliminary stage of the engine design process as it provides insight information for the 373 engine performance and emission parameters trade-offs. 

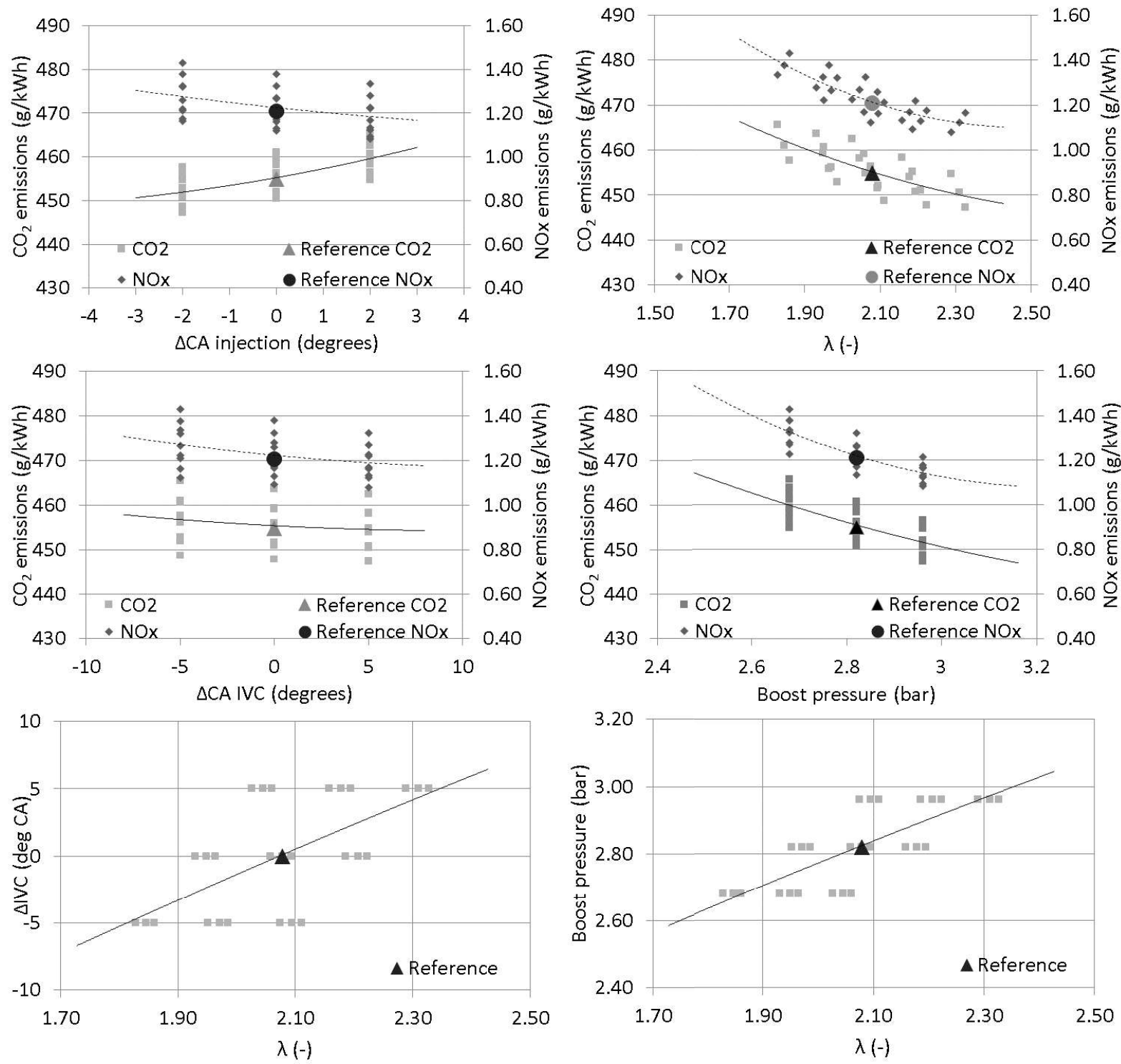

Figure 7 Parametric study results for DF engine operation at $75 \%$ load 
379

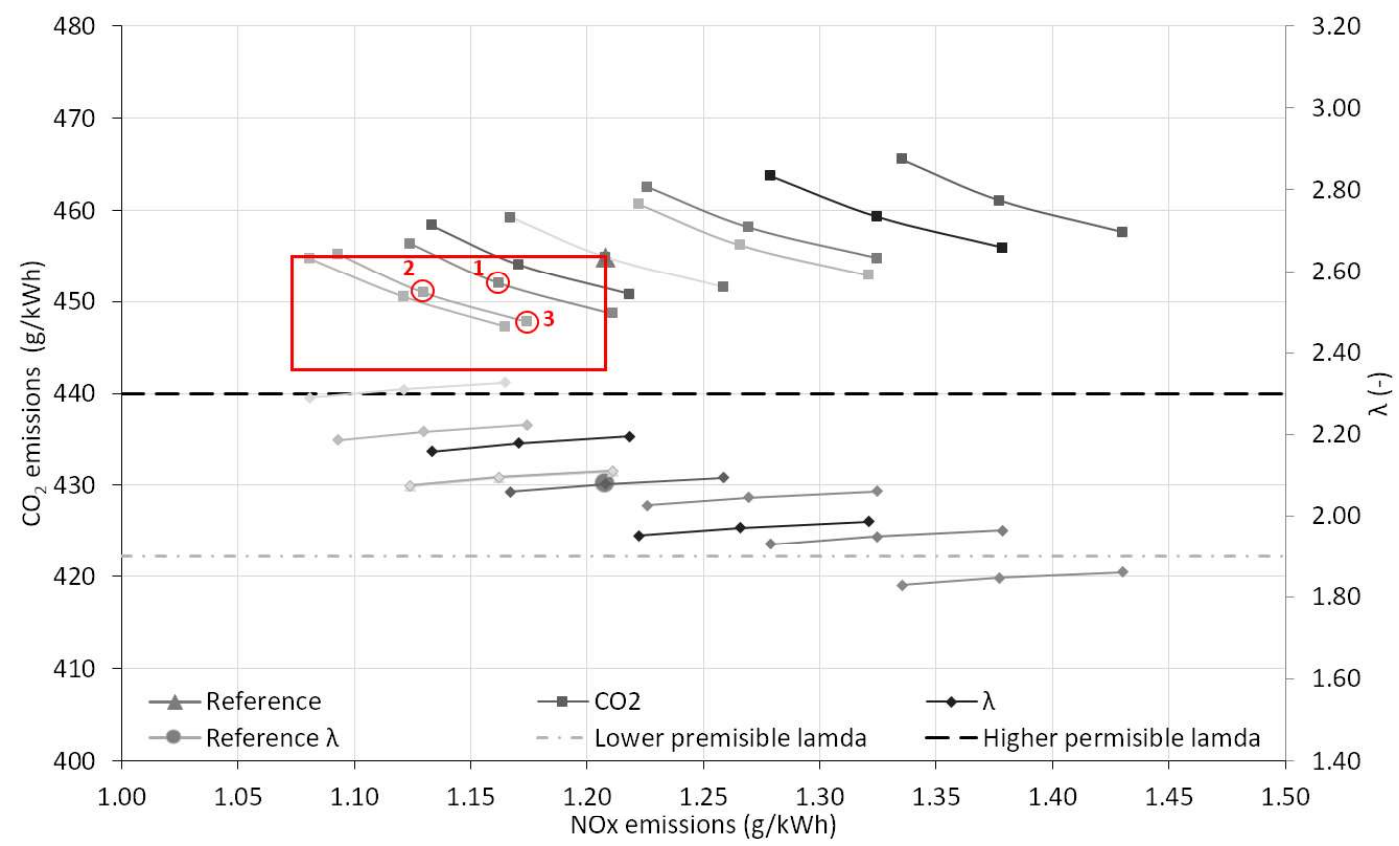

Figure 8 Parametric study results for DF engine operation at $75 \%$ load showing potential for $\mathrm{CO}_{2}$ and $\mathrm{NOx}$ emissions reduction
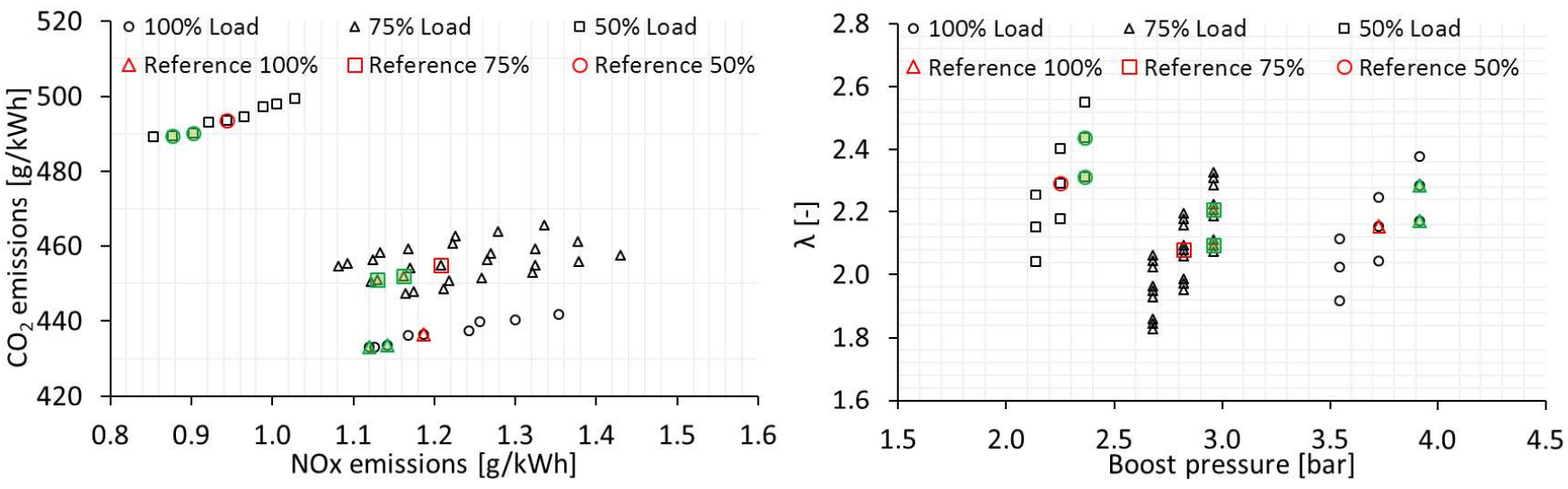

Figure 9 Parametric study results for DF engine operation at 50\% and $100 \%$ load

380 Table 4 Optimised points from parametric runs

\begin{tabular}{|c|c|c|c|c|c|c|c|c|c|}
\hline Load & No. & $\Delta \mathrm{IVC}$ & $\begin{array}{l}\Delta \text { Boost } \\
\text { pressure }\end{array}$ & $\begin{array}{l}\Delta \text { Pilot } \\
\text { Injection } \\
\text { timing }\end{array}$ & Lamda & NOx & $\mathrm{CO}_{2}$ & $\Delta \mathrm{NOx}$ & $\Delta \mathrm{CO}_{2}$ \\
\hline$(\%)$ & $(-)$ & $\left({ }^{\circ} \mathrm{CA}\right)$ & $(\%)$ & $\left({ }^{\circ} \mathrm{CA}\right)$ & $(-)$ & $(\mathrm{g} / \mathrm{kWh})$ & $(\mathrm{g} / \mathrm{kWh})$ & $(\%)$ & $(\%)$ \\
\hline \multirow{2}{*}{$50 \%$} & - & 0 & 5 & 0 & 2.31 & 0.9 & 490.3 & -4.4 & -0.7 \\
\hline & - & 5 & 5 & 0 & 2.44 & 0.88 & 489.5 & -7.2 & -0.8 \\
\hline \multirow{3}{*}{$75 \%$} & 1 & 0 & 5 & 0 & 2.09 & 1.16 & 452 & -3.8 & -0.6 \\
\hline & 2 & 5 & 5 & 0 & 2.21 & 1.13 & 451 & -6.5 & -0.9 \\
\hline & 3 & 5 & 5 & -2 & 2.22 & 1.17 & 447.8 & -2.8 & -1.6 \\
\hline \multirow{2}{*}{$100 \%$} & - & 0 & 5 & 0 & 2.17 & 1.14 & 433.6 & -3.8 & -0.7 \\
\hline & - & 5 & 5 & 0 & 2.28 & 1.12 & 433 & -5.7 & -0.8 \\
\hline
\end{tabular}


In the present study, a marine four-stroke dual fuel engine was investigated by using GT-ISE software in both diesel and gas mode operation. The engine performance and emissions parameters for both modes were compared and discussed. Parametric runs were performed and the results were used for deriving the engine setting that provide a simultaneous reduction of $\mathrm{CO}_{2}$ and $\mathrm{NOx}$ emissions considering the engine operating limitations. The main findings of the conducted research are summarised as follows:

- The developed model can predict with adequate accuracy the engine performance and emissions parameters both for the diesel and DF operation and can be used in the preliminary stage of the engine design process for optimising the engine settings.

- The engine in the gas mode operates with almost constant air-fuel equivalence ratio in a narrow window from 2.0 to 2.3 , whereas slightly higher values of the air-fuel equivalence ratio are used for the diesel mode corresponding to greater air flow rates. This is obtained by controlling waste gate valve opening (for gas mode) to adjust the engine air flow and therefore the air-fuel ratio. Special attention must be paid during the turbocharger matching process as there are different requirements in each operating mode including avoidance of turbocharger overspeed, providing an adequate compressor surge margin and operating the compressor within its high efficiency area.

- In the gas mode, the engine operates at lower receivers and in-cylinder pressure level. However, the mean effective pressure and power output is kept at the diesel mode levels due to the shorter combustion duration and the earlier start of combustion.

- The gas mode is more efficient than diesel mode at the high load region; however, less efficient operation was observed at the lower load region.

- The NOx emissions reduced by $85 \%$ in average in the gas mode compared with the diesel mode. 404 The diesel mode complies with the Tier II limits, whereas Tier III limits are met when the engine 405 operated in the gas mode.

406 - Increasing the engine boost pressure and/or retarding the Miller timing inlet valve closing can 407 result in $\mathrm{NOx}$ and $\mathrm{CO}_{2}$ emissions reduction. 
- Compared to the reference point settings, the engine $\mathrm{NOx}$ and $\mathrm{CO}_{2}$ emissions can be reduced up to $6 \%$ and $1.6 \%$, respectively by increasing the inlet boost pressure by $5 \%$ and/or by retarding the 410 Miller timing inlet valve closing by 5 degrees CA. However, limitations apply due to air-fuel ratio 411 operation window and the potential hydrocarbon emissions (methane slip) increase. 912

417 be considered and adopted in the future ship designs. The obtained results can be used as guidance 418 during the design process of the dual fuel engines or when designing a vessel energy management 419 system. 
Brake efficiency (-)

Eff

FF

$\mathrm{P}_{\mathrm{b}}$

$p_{\max }$ $\mathrm{x}_{\mathrm{b}}(\theta) \mathrm{m}$

$\triangle \mathrm{IVC}$

$\Delta \theta$

$\theta$

$\lambda$

\section{ABBREVIATIONS}

OD

$1 \mathrm{D}$

3D

BMEP

BSEC

BSFC

$\mathrm{CA}$

$\mathrm{CO}$

$\mathrm{CO}_{2}$

DF

ECA

ECU

EEDI

EEOI

$\mathrm{HC}$

HFO

IMO

LNG

MARPOL

MCR

MGO

NG

NOx

PM

SEEMP

SOC

$\mathrm{SOx}$

TDC

$\mathrm{T} / \mathrm{C}$
Fuel fraction per Wiebe Curve (-)

Brake power (kW)

Maximum cylinder pressure (bar)

Burning rate as a function of crank angle

Inlet valve closing difference

Combustion duration (deg CA)

Crank angle $(0=$ TDC $)$

Air-fuel equivalence ratio (-)

Normalised time used in Wiebe function (-)

Zero-dimensional

One-dimensional

Three-dimensional

Brake Mean Effective Pressure

Brake Specific Energy Consumption

Brake Specific Fuel Consumption

crank angle

Carbon Monoxide

Carbon Dioxide

Dual Fuel

Emission Control Area

Engine Control Unit

Energy Efficiency Design Index

Energy Efficiency Operational Indicator

Hydrocarbons

Heavy Fuel Oil

International Maritime Organization

Liquefied Natural Gas

International Convention for the Prevention of Marine Pollution

Maximum continuous rating

Marine Gas Oil

Natural Gas

Nitrogen Oxides

Particular Matter

Ship Energy Efficiency Management Plan

Start of combustion

Sulphur Oxides

Top Dead Centre

Turbocharger 
AKNOWLEDGMENTS

Gamma Technologies support is greatly acknowledged by the authors.

\section{REFERENCES}

Abagnale, C., Cameretti, M., De Simio, L., M., G., Iannaccone, S., \& Tuccillo, R. (2014). Numerical simulation and experimental test of dual fuel operated diesel engines. Applied Thermal Engineering, 403-417. doi:http://dx.doi.org/10.1016/j.applthermaleng.2014.01.040

Abdelrahman, H., Antonino, L. R., \& Paul, S. (2016). Towards keeping diesel fuel supply and demand in balance: Dual-fuelling of diesel engines with natural gas. Renewable and Sustainable Energy Reviews. doi:http://dx.doi.org/10.1016/j.rser.2016.11.249

ABS. (2013). Ship Energy Efficiency Measures - Status and Guidance. Publication No. TX 05/13 500013015.

Amit, B., Markus, K., Luca, M., \& Fabian, M. (2004). Modelling a Dual-fuelled Multi-cylinder HCCI Engine Using a PDF based Engine Cycle Simulator. $S A E$.

Andre, R. (2013). Dual-Fuel for maritime application. In Proceedings of the 27th CIMAC World Congress on Combustion Engine Technology, Shanghai, China, 13-16 May 2013; Paper no. 204.

Ashok, B., Denis, S., Ashok, C., \& Ramesh, K. (2015, April 1). LPG diesel dual fuel engine - A critical review. Alexandria Engineering Journal. doi:http://dx.doi.org/10.1016/j.aej.2015.03.002

Baldi, F., Theotokatos, G., \& Andersson, K. (2015). Development of a combined mean value zero dimensional model and application for a large marine four-stroke Diesel engine simulation. Applied Energy. 154; 402-415.

Banck A., Eike, S., \& Carsten, R. (2016). Dual Fuel Engine optimized for marine applications. 28th CIMAC World Congress 2016 (p. 047). Helsinki: CIMAC.

Benvenuto, G., Campora, U., \& Laviola, M. (2013). Simulation Model of a Methane-Fuelled Four Stroke Marine Engine for Studies on Low Emission Propulsion Systems. IMAM 2013, 15th International Congress on Maritime Association of the Mediterranean (pp. Pages 591-597). Acorugna, Spain: CRC Press 2013. doi:10.1201/b15813-72

Bo, Y., Chengxun, X., Xing, W., Ke, Z., \& Ming-Chia, L. (2015). Parametric investigation of natural gas port injection and diesel pilot injection on the combustion and emissions of a turbocharged common rail dual-fuel engine at low load. Applied Energy, 130-137. doi:http://dx.doi.org/10.1016/j.apenergy.2015.01.037

Boeckhoff, N., Heider, G., \& Hagl, P. (2010). Operational experience of the 51/60 DF from MAN Diesel SE, PAPER NO.: 37. CIMAC. Bergen.

Bows-Larkin, Mander, A., Gilbert, S., Traut, P., \& Walsh, M. (2014). High Seas, High Stakes, High Seas Final Report. University of Manchester, School of Mechanical Aerospace and Civil Engineering. Tyndall Centre for Climate Change Research. Retrieved from http://www.lowcarbonshipping.co.uk/files/ucl_admin/High_Seas_High_Stakes_High_Seas_Project_Fi nal_Report.pdf

Cameretti, M., Tuccillo, R., De Simio, L., Iannaccone, S., \& Ciaravola, U. (2016). A numerical and experimental study of dual fuel diesel engine for different injection timings. Applied Thermal Engineering, 630-638. doi:http://dx.doi.org/10.1016/j.applthermaleng.2015.12.071

Christen, C. and Brand, D. (2013). IMO Tier 3: Gas and dual fuel engines as a clean and efficient solution. Paper no. 187. 27th CIMAC World Congress on Combustion Engine Technology, Shanghai, China, 13-16 May 2013.

Cichowicz, J., Theotokatos, G., \& Vassalos, D. (2015). Dynamic energy modelling for ship life-cycle performance assessment. Ocean Engineering, 110, 49-61.

CIMAC (2012). EMISSION CALCULATION CHECK GUIDE - IMO NOx Technical Code 2008. The International Council on Combustion Engines, Working Group 'Exhaust Emissions Control' Members. http://www.cimac.com/cms/upload/workinggroups/WG5/CIMAC_Exhaust_Emissions_Control_Qualit y_Guide_IMO_NOx_Technical_Code_2008_FINAL.pdf[Accessed 23 Dec 2017]. 
CIMAC. (2011). TRANSIENT RESPONSE BEHAVIOUR. CIMAC WORKING GROUP "GAS ENGINES". Frankfurt: CIMAC.

Ciulli, E. (1993). A review of internal combustion engine losses, pt. 2: studies for global evaluations. Proceedings of the Institution of Mechanical Engineers, Part D: Journal of Automobile Engineering, 207(3), pp.229-240.

Coble, A., Smallbone, A., Bhave, A., Mosbach, S., Kraft, M., Niven, P. and Amphlett, S. (2011). Implementing Detailed Chemistry and In-Cylinder Stratification into 0/1-D IC Engine Cycle Simulation Tools. SAE Technical Paper Series 2011-01-0849. doi:10.4271/2011-01-0849.

Cordiner, S., Rocco, V., Scarcelli, R., Gambino, M., Iannaccone, s., \& Setaro, G. (2005). Numerical and Experimental Analysis of the Behaviour of a Heavy-Duty Diesel Engine Converted to Dual-Fuel Operations. SAE Technical Paper 2005-24-032. doi:10.4271/2005-24-032

EMSA. (2015). emsa.europa.eu. Retrieved from em-sa.europa.eu/main/air-pollution.html.

EPA. (2010). Control of Emissions from New Marine Compression-Ignition Engines at or Above 30 Liters per Cylinder; Final Rule. Federal Register/Rules and Regulations. 75(83), 30 April 2010.

EPA. (2015). www.epa.gov. Retrieved from www.epa.gov/otaq/marine.htm.

Bouman E., Lindstad E., Rialland A., Strømman A. (2017). State-of-the-art technologies, measures, and potential forreducing GHG emissions from shipping - A review. Transportation Research Part D, 408-421. doi:http://dx.doi.org/10.1016/j.trd.2017.03.022

Gamma Technologies. (2016). GT Reference Manual.

Georgescu, I., Douwe, S., \& Benny, M. (2016). Dynamic Behaviour of Gas and Dual-Fuel Engines: Using Models and Simulations to Aid System Integration, PAPER NO.: 126. 28th CIMAC World Congress 2016. Helsinki.

Hendrik, L., Andreas, B., \& Eike, S. (2016). Investigation of alternative dual fuel engine concepts. 28th CIMAC World Congress 2016 (p. 212). Helsinki.

Heywood, J. B. (1998). Internal combustion engine fundamentals. Mc-Graw-Hill, Inc.

Hoenders R. (2013). EU Initiatives regarding the use of LNG as bunker fuel and EMSA's involvement in promoting the use of LNG as alternative fuel. European Maritime Safety Agency (EMSA). July 2013.

IMO. (2014). MARPOL Annex VI, Regulation 13.

IMO. (2014). MARPOL Annex VI, Regulation 14.

Jarf, C., \& Sutkowski, M. (2009). The Wärtsilä 32GD engine for heavy gases. (Wärtsilä) Retrieved January 2018, from Polish Scientific Society of Combustion Engines: http://www.combustionengines.eu/en/numbers/36/147

Jarvi, A. (2010). Methane slip reduction in Wartsila lean burn gas, PAPER NO.: 106. 26th CIMAC World Congress 2010. Bergen, Norway.

Jean-Michael H. (2012). Retrofit of Wärtsilä diesel engine to Dual fuel. Colloque optimisation énergétique des navires. Marseille.

Karim, G. (March 2, 2015). Dual-Fuel engines. CRC Press, Taylor \& Francis Group.

Kavtaradze, R. Z., Zeilinger, K., \& Zitzler, G. (2005). Ignition Delay in a Diesel Engine Utilizing Different Fuels. High Temperature, 43(6), 947-956.

Krishnan, S. R. (2002). Performance and heat release analysis of a pilot-ignited natural gas engine. International Journal of Engine Research, 3(3), 171-184.

Kyriakides, N., Chryssakis, C. and Kaiktsis, L. (2009). Influence of Heavy Fuel Properties on Spray Atomization for Marine Diesel Engine Applications. SAE Technical Paper Series.

Li, Y. (2016). Research on the Influence of Diesel Injection Law to Combustion Process of Micro Ignition Dual Fuel Engine, PAPER NO.: 306. 28th CIMAC World Congress 2016. Helsinki.

Liu, Z., \& Karim, G. (1997). Simulation of combustion pro-cesses in gas-fuelled diesel engines. Proceedings of the Institution of Mechanical Engineers, Part A: Journal of Power and Energy, 211(2):159-169/1997.

Livanos, G., Theotokatos, G., \& Pagonis, D. (2014). Techno-economic investigation of alternative propulsion plants for ferries and roro ships. Energy Conversion and Management, (pp. 79:640-651). doi:10.1016/j.enconman.2013.12.05

MAN Diesel \& Turbo. (2012). SFOC Optimization Methods for MAN B\&W Two-Stroke IMO Tier II Engines,. MAN Diesel \& Turbo: Augsburg, Germany; Publication no. 5510-0099-00ppr. 
MAN Diesel \& Turbo. (2015). ME-GI Gas-ready Ship. MAN Diesel \& Turbo. Publication No. 5510-0176o0ppr, Aug 2015, Denmark.

Mavrelos, C., \& Theotokatos, G. (2018). Numerical Investigation of a Premixed Combustion Large Marine Two-Stroke Dual Fuel Engine for Optimising Engine Settings via Parametric Runs. Energy Conversion and Management.

Menghan, L., Qiang, Z., Guoxiang, L., \& S. S. (2015). Experimental investigation on performance and heat release analysis of a pilot ignited direct injection natural gas engine. Energy, 1-10. doi:http://dx.doi.org/10.1016/j.energy.2015.06.089

Merker, G., Schwarz, C., Stiesch, G., \& Otto, F. (2006). Simulating Combustion. Berlin, Germany: SpringerVerlag.

Mizythras P, Boulougouris E, Theotokatos G. (2018) Numerical study of propulsion system performance during ship acceleration, Ocean Engineering. 10.1016/j.oceaneng.2017.12.010

Mohand Said, L., Khaled, L., Lyes, T., \& Mourad, B. (2013). Towards improvement of natural gas-diesel dual fuel mode: An experimental investigation on performance and exhaust emissions. Energy, 200-211. doi:http://dx.doi.org/10.1016/j.energy.2013.10.091

Mohr, H., \& Baufeld, T. (2013). Improvement of dual-fuel-engine technology for current and future applications, PAPER NO.: 412. CIMAC. Shanghai.

Moriyoshi, Y., Xiong, Q., Kuboyama, T. and Morikawa, K. (2016). Combustion Analysis in a Natural Gas Engine with Pre-Chamber to Improve Thermal Efficiency. In Proceedings of the 28th CIMAC World Congress on Combustion Engine Technology, Helsinki, Finland, 6-10 June 2016

Nylund I., \& Ott, M. (2013). Development of a Dual Fuel technology for slow-speed engines, Paper No. 284. 27th CIMAC World Congress 2013. Shanghai, China.

Nylund, I. (2007). Field expirience with the Wärtsilä 50DF Dual fuel engine, PAPER NO.: 239. CIMAC. Vienna.

Ozcan, H., \& Yamin, J. (2008). Performance and emission characteristics of LPG powered four stroke SI engine under variable stroke length and compression ratio. Energy Conversion and Management, 49(5), 1193 1201. http://dx.doi.org/10.1016/j.enconman.2007.09.004

Papagianakis, R., Rakopoulos, C., Hountalas, D., \& Rakopoulos, D. (2010). Emmision characteristics of high speed, dual fuel, compression ignition engine operating in a wide range of natural gas/diesel fuel proportions. FUEL - 17th International Symposium on Alcohol Fuels, 89, 1397-1406. doi:10.1016/j.fuel.2009.11.001

Pirker, G., Losonczi, B., Fimml, W., Wimmer, A. and Chmela, F. (2010). Predictive Simulation of Combustion and Emissions in Large Diesel Engines with Multiple Fuel Injection. In Proceedings of the 26th CIMAC World Congress on Combustion Engine Technology, Bergen, Norway, 14-17 June 2010; Paper no. 235.

Portin, K. (2010). Wärtsilä dual fuel (DF) enines for offshore applications and mechanical drive, PAPER NO.: 112. CIMAC. Bergen.

Qiang, Z., Na, L., \& Menghan, L. (2015). Combustion and emission characteristics of an electronicallycontrolled common-rail dual-fuel engine. Journal of the Energy Institute, 766-781. doi:http://dx.doi.org/10.1016/j.joei.2015.03.012

Ritzke, J., Andree, S., Theile, M., Henke, B., Schleef, K., Nocke, J. and Hassel, E. (2016). Simulation of a DualFuel Large Marine Engines using combined 0/1-D and 3-D Approaches. In: The International Council on Combustion Engines. In Proceedings of the 28th CIMAC World Congress on Combustion Engine Technology, Helsinki, Finland, 6-10 June 2016; Paper no. 213.

Savva, N. and Hountalas, D. (2014). Evolution and application of a pseudo-multi-zone model for the prediction of NOx emissions from large-scale diesel engines at various operating conditions. Energy Conversion and Management, 85, pp.373-388.

Shinsuke, M., Thomas, K., Robert, S., Michael, Z., Ingo, K., \& Andrei, L. (2016). Holistic Approach for Performance and Emission Development of High Speed Gas and Dual Fuel Engines. 28th CIMAC World Congress 2016 (p. 273). Helsinki. 
Shuonan, X., David, A., Amrit, S., \& Mark, H. (2014). Development of a Phenomenological Dual-Fuel Natural Gas Diesel Engine Simulation and Its Use for Analysis of Transient Operations. SAE. doi:10.4271/2014-01-2546

Singh, S., Kong, S., Reitz, R., Krishnan, S., \& al., e. (2004). Modelling and Experiments of Dual-Fuel Engine Combustion and Emissions. SAE Technical Paper 2004-01-0092. doi:10.4271/2004-01-0092

Sixel, E. J., Hiltner J., \& Rickert C. (2016). Use of 1-D simulation tools with a physical combustion model for the development of Diesel-Gas or Dual Fuel engines, PAPER NO.: 124. 28th CIMAC World Congress 2016. Helsinki.

Srinivasan, K., Krishnan, S., \& Midkiff, K. (2006). Improving low load combustion, stability and emissions in pilot-ignited natural gas engines. Proceedings of the Institution of Mechanical Engineers, Part D: Journal of Automobile Engineering, 220, pp. 229-239. doi:10.1243/09544070JAUTO104

Theotokatos, G., \& Tzelepis, V. (2015). A Computational study on the performance and emissions parameters mapping of a ship propulsion system. Proc. IMechE Part M: J. Eng. Mar. Environ. 229, 58-76.

Theotokatos, G., Stoumpos, S., Lazakis, I., \& Livanos, G. (2016). Numerical study of a marine dual-fuel fourstroke engine. In C. G. Soares, \& T. A. Santos (Eds.), Maritime Technology and Engineering III: Proceedings of the 3rd International Conference on Maritime Technology and Engineering (MARTECH 2016, Lisbon, Portugal, 4-6 July 2016). (Vol. 2, pp. 777-783). London. DOI: $10.1201 / \mathrm{b} 21890-100$

Vasil'ev, A. (2007). Ignition Delay in Multifuel Mixtures. Combustion, Explosion, and Shock Waves, 43(3), 282-285.

Wang, B., Li, T., Ge, L., \& Ogawa, H. (2016). Optimization of combustion chamber geometry for natural gas engines with diesel micro-pilot-induced ignition. Energy Conversion and Management, 122, 552-563. http://dx.doi.org/10.1016/j.enconman.2016.06.027

Wang, H., Kolmanovsky, I., Sun, J., \& Ozaki, Y. (2015). Feedback control during mode transition for a marine dual fuel engine. International Federation of Automatic Control (IFAC) Papers on Line, 279-284. doi:10.1016/j.ifacol.2015.10.293

Wärtsilä. (2015). Improving engine fuel and operational efficiency. Wärtsilä services business white paper engine fuel and operational efficiency. Retrieved from http://cdn.wartsila.com/docs/defaultsource/services-documents/white-papers/wartsila-bwp-improving-engine-fuel-and-operationalefficiency-2015.pdf?sfvrsn=6

Wärtsilä. (2015). Product Guide Wärtsilä 50DF. Wärtsilä. Retrieved from http://www.wartsila.com/products/marine-oil-gas/engines-generating-sets/dual-fuel-engines/wartsila50df: $\quad$ http://www.wartsila.com/products/marine-oil-gas/engines-generating-sets/dual-fuelengines/wartsila-50df

Wei, H., Chen, X., Wang, G., Zhou, L., An, S. and Shu, G. (2017). Effect of swirl flow on spray and combustion characteristics with heavy fuel oil under two-stroke marine engine relevant conditions. Applied Thermal Engineering, 124, pp.302-314. https://doi.org/10.1016/j.applthermaleng.2017.05.202

Weifeng, L., Zhongchang, L., \& Zhongshu, W. (2015). Experimental and theoretical analysis of the combustion process at low loads of a diesel natural gas dual-fuel engine. Energy, 728-741. doi:http://dx.doi.org/10.1016/j.energy.2015.11.052

Woschni, G. (1967). A Universally Applicable Equation for the Instantaneous Heat Transfer Coefficient in the Internal Combustion Engine (Vol. 76). SAE Technical Paper 670931. doi:10.4271/670931

Xu, S., Anderson, D., Singh, A., Hoffman, M., Prucka, R., \& Filipi., Z. (2014). Development of a Phenomenological Dual-Fuel Natural Gas Diesel Engine Simulation and Its Use for Analysis of Transient Operations. SAE Int. J. Engines. 7(4). 1665-1673.

Yang, L., Song, E., Ding, S., Brown, R., Marwan, N. and Ma, X. (2016). Analysis of the dynamic characteristics of combustion instabilities in a pre-mixed lean-burn natural gas engine. Applied Energy, 183, pp.746759.

Yousefi, A., Birouk, M., Lawler, B., \& Gharehghani, A. (2015). Performance and emissions of a dual-fuel pilot diesel ignition engine. Energy Conviention Management, Paper No. JERT-16-1051. doi:10.1115/1.4033707 
623 Zhongshu, W., Zhongxiang, Z., Dan, W., Manzhi, T., Yongqiang, H., \& Zhongchang, L. (2015). Impact of pilot diesel ignition mode on combustion and emissions characteristics of a diesel/natural gas dual fuel heavy-duty engine. Fuel, 248-256. doi:http://dx.doi.org/10.1016/j.fuel.2015.11.077 